\title{
EL PERONISMO EN CORRIENTES. ENTRE LA FRUSTRACIÓN DE LA DERROTA ELECTORAL Y LA CONQUISTA DEL PODER POLÍTICO
}

\author{
(1946- 1948)
}

\author{
Redefining Strategies. The Correntinean Peronism between being Electorally Defeated \\ and Conquering the Political Power (1946-1948)
}

\section{María del Mar Solís Carnicer}

\section{Resumen}

En las elecciones de febrero de 1946 el peronismo se consagró triunfador en todo el país, no solo accedió a la presidencia de la República y consiguió una abrumadora mayoría en la Cámara de Diputados de la Nación sino que logró imponer sus fórmulas en los gobiernos de casi todas las provincias, con una sola excepción, la provincia de Corrientes, en la que resultó ganadora la fórmula radical. Esta situación peculiar derivó en un conflictivo proceso político e institucional que obligó al peronismo correntino a reformular sus estrategias políticas en la provincia, reorganizar sus fuerzas y redefinir su identidad. Una intervención federal decretada por el gobierno nacional en septiembre de 1947 fue parte de ese proyecto, en el que se incluyó una reforma al sistema electoral de la provincia y una política de acercamiento a los partidos conservadores.

En este trabajo buscamos analizar ese proceso, que se inicia a partir de la derrota electoral de 1946 y que finaliza con el triunfo de la fórmula proclamada por el peronismo en las elecciones provinciales de diciembre de 1948. En un intento por establecer ciertas pautas comunes que permitan la comparación nos concentramos exclusivamente en las elecciones ejecutivas provinciales, dejando de lado las demás. Asimismo, prestamos especial atención a las estrategias políticas y electorales empleadas en cada caso, así como a la reconstrucción historiográfica del proceso de reorganización interna del peronismo durante ese período.

$<$ Peronismo $><$ Historia polític $><$ Estrategias electorales $><$ Corrientes $>$

\begin{abstract}
By wining the national elections in February, 1946, the peronism obtained the Presidency, the majority at the Representative Chamber, and most of the State governments with the exception of Corrientes where the radicales imposed. This particular situation led to a conflictive institutional and political process that in turn derived in the reformulation of the Correntinean peronist political strategies, identities and forces. A federal intervention in 1947 ordered by the federal government was part of this project. This included the reform of the electoral system in the province and a
\end{abstract}


policy of affinity with the conservative parties. In this study we examine this process from the 1946 till December 1948, with a particular focus on the executive elections. In addition, we are interested in examining the electoral and political strategies, as well as the historiographic reconstruction of peronist organization in this period.

$<$ Peronism $><$ political history $><$ electoral strategies $><$ corrientes $>$

\section{Introducción}

En las elecciones de febrero de 1946 el peronismo se consagró triunfador en todo el país, no solo accedió a la presidencia de la República y consiguió una abrumadora mayoría en la Cámara de Diputados de la Nación sino que logró imponer sus fórmulas en los gobiernos de casi todas las provincias, con una sola excepción, la provincia de Corrientes, en la que resultó ganadora la fórmula radical. Esta situación peculiar derivó en un conflictivo proceso político e institucional que obligó al peronismo correntino a reformular sus estrategias políticas en la provincia, reorganizar sus fuerzas y redefinir su identidad. Una intervención federal decretada por el gobierno nacional en septiembre de 1947 fue parte de ese proyecto, en el que se incluyó una reforma al sistema electoral de la provincia y una política de acercamiento a los partidos conservadores.

En este trabajo buscamos analizar ese proceso, que se inicia a partir de la derrota electoral de 1946 y que finaliza con el triunfo de la fórmula proclamada por el peronismo en las elecciones provinciales de diciembre de 1948. En un intento por establecer ciertas pautas comunes que permitan la comparación nos concentraremos exclusivamente en las elecciones ejecutivas provinciales, dejando de lado las demás; asimismo, prestaremos especial atención a las estrategias políticas y electorales empleadas en cada caso, así como a la reconstrucción historiográfica del proceso de reorganización interna del peronismo durante ese período.

Los periódicos de la época de las diversas tendencias políticas y los testimonios de referentes del primer peronismo fueron las fuentes sobre las cuales sustentamos esta investigación.

\section{I- La elecciones provinciales de 1946 y 1948}

Tanto en 1946 como en 1948 se realizaron elecciones ejecutivas en la provincia de Corrientes, en ambos casos fue una intervención federal la encargada de organizarlas y su ocurrencia coincidió con elecciones nacionales presidenciales y legislativas en el primero y a convencionales constituyentes, en el segundo. En las dos, además, se elegían diputados y senadores provinciales. Sin embargo, los resultados fueron muy distintos. En la primera, resultó triunfadora la fórmula gubernativa proclamada por el radicalismo mientras que en la segunda, llevada a cabo solo dos años y nueve meses después, el peronismo obtuvo un amplio triunfo. Realizaremos aquí una breve descripción de las 
mismas y de sus resultados para luego, en los siguientes apartados, dedicarnos al análisis de lo que consideramos fueron las principales estrategias que colaboraron con dicho cambio: la reforma del sistema electoral y la reorganización del Partido Peronista.

En las elecciones provinciales del 24 febrero de 1946, se presentaron siete fórmulas gubernativas. La propuesta por el Partido Demócrata Nacional - Distrito Corrientes (PDN- Ctes) y el Antipersonalismo (Elías Abad- Carlos Lotero Silgueira), la Radical (Blas Benjamín de la Vega- Pedro Villar), la Autonomista (Diómedes Rojas- Fernando Romero Corrales), la Liberal (Ernesto Meabe- Mariano Gómez), la del Partido Demócrata Progresista- Comunista (Justo Alvarez Hayes- José Rosenbaum), la Laborista (José Ramón Virasoro- Santiago Ballejos) y la de la Unión Cívica Radical -Junta Renovadora (UCR- JR) (Pedro Díaz de Vivar- Santiago Ballejos). Es decir que el sector del peronismo se presentó dividido, lo mismo que el conservador que estuvo repartido en tres fórmulas.

La campaña política fue corta pero muy intensa, con la realización de mítines, asambleas, manifestaciones públicas, caravanas, conferencias y transmisiones radiales. Por momentos se vivieron situaciones tensas al producirse algunos enfrentamientos y hechos de violencia. A pesar de ser elecciones generales para todos los cargos, la campaña se polarizó en torno a las candidaturas presidenciales. El peronismo era identificado por las demás fuerzas políticas con el fascismo y el nazismo y era común encontrar en los periódicos referencias al "naziperonismo". Durante la campaña los diferentes partidos políticos que se enfrentaban al peronismo se preocuparon por definir su confrontación con el "oficialismo" a través de la defensa del restablecimiento de las libertades y garantías democráticas. Se creían representantes de la libertad frente al "nazifascismo" que veían encarnado en el peronismo.

Las alusiones a las libertades democráticas eran comunes en el discurso de todas las fuerzas antiperonistas como uno de los rasgos que los diferenciaba del otro sector. Los comunistas y los demócratas, además, agregaron a su propaganda la identificación de sus partidos con las reivindicaciones de las clases trabajadoras, buscando conseguir el apoyo de ese sector, que en forma masiva se había volcado hacia el peronismo.

Las elecciones, realizadas el 24 de febrero, se llevaron a cabo en un clima de tranquilidad. El número total de votantes fue de 93.340 , lo que correspondía al 73,65\% del padrón electoral que se componía de 126.202 ciudadanos. En general, en casi todos los departamentos de la provincia, el nivel de participación superó el $70 \%$ lo que demuestra el alto interés que generaron estas elecciones. La opinión favorable acerca de la realización de los comicios fue generalizada.

Según los datos volcados en las Tablas $\mathrm{N}^{\circ} 1$ y 2 , de todos los partidos participantes, el Laborista con 18.391 votos (19,9\%) fue el que obtuvo mayor número de sufragios. Sin embargo, como los antipersonalistas y el PDN (DC) votaron por la misma fórmula, esto la convirtió en la más votada de la provincia $(21 \%){ }^{1}$

\footnotetext{
${ }^{1}$ Al partido laborista lo siguió el Partido Radical (CN) con 16.900 votos (18,3\%), el liberal con 15.627 (16,9\%), la UCR (JR) con 15.428 (16,8\%), el PDN (DC) con 13.660 (14,3\%), los Antipersonalistas con $5.785(6,3 \%)$, los Autonomistas con $5842(6,3 \%)$ y la Alianza Comunista- PDP con 572 votos $(0,6 \%)$.
} 
El Partido Laborista se impuso en 8 de los 24 departamentos de la provincia (todos los de la costa del río Uruguay, además de Capital, Goya, Sauce e Itatí) ${ }^{2}$, el PDN (DC) en 6 departamentos, el Partido Liberal y la UCR (JR) en 4 departamentos cada uno y la UCR $(\mathrm{CN})$ en 2 departamentos. (Véase Mapa $\mathrm{N}^{\circ} 1$ ).

Tabla $N^{\circ} 1$. Resultados de las elecciones de 1946 por departamento

\begin{tabular}{|l|r|r|r|r|r|r|r|r|}
\hline & Concordancia & UCR & LIBERAL & AUTONOM & $\begin{array}{c}\text { LABO- } \\
\text { RISTAS }\end{array}$ & UCR JR & $\begin{array}{c}\text { PDP- } \\
\text { Com }\end{array}$ & TOTAL \\
\hline Capital & 2409 & 1759 & 923 & 641 & 4120 & 3396 & 194 & 13442 \\
\hline Empedrado & 828 & 350 & 474 & 726 & 340 & 808 & 21 & 3547 \\
\hline Bella Vista & 1083 & 967 & 624 & 328 & 81 & 635 & 9 & 3727 \\
\hline Esquina & 885 & 1612 & 717 & 53 & 1089 & 146 & 4 & 4506 \\
\hline Monte Caseros & 259 & 329 & 543 & 71 & 1545 & 890 & 19 & 3656 \\
\hline San Martín & 706 & 762 & 753 & 195 & 1400 & 166 & 4 & 3986 \\
\hline Ituzaingó & 702 & 277 & 589 & 21 & 160 & 464 & 3 & 2216 \\
\hline Goya & 904 & 2036 & 1955 & 414 & 3269 & 945 & 89 & 9612 \\
\hline Berón de Astrada & 222 & 134 & 49 & 9 & 0 & 58 & 0 & 472 \\
\hline General Paz & 1212 & 449 & 371 & 206 & 195 & 794 & 6 & 3233 \\
\hline Concepción & 529 & 555 & 634 & 209 & 50 & 397 & 8 & 2382 \\
\hline San Roque & 762 & 724 & 739 & 253 & 70 & 505 & 6 & 3059 \\
\hline Curuzú Cuatiá & 1912 & 799 & 727 & 260 & 1174 & 1326 & 13 & 6211 \\
\hline Sauce & 616 & 290 & 452 & 88 & 552 & 29 & 0 & 2027 \\
\hline Santo Tomé & 269 & 1000 & 368 & 101 & 1145 & 699 & 74 & 3656 \\
\hline San Cosme & 543 & 244 & 266 & 190 & 88 & 467 & 5 & 1803 \\
\hline San Luis & 1374 & 385 & 766 & 343 & 51 & 573 & 3 & 3495 \\
\hline Iratí & 219 & 230 & 37 & 105 & 270 & 34 & 2 & 897 \\
\hline San Miguel & 421 & 376 & 312 & 303 & 36 & 174 & 1 & 1623 \\
\hline Mburucuyá & 514 & 368 & 404 & 270 & 21 & 576 & 4 & 2157 \\
\hline Saladas & 903 & 557 & 560 & 228 & 455 & 837 & 13 & 3553 \\
\hline Lavalle & 751 & $\mathrm{~S} / \mathrm{D}$ & 1532 & 457 & 290 & 438 & 7 & 4337 \\
\hline Mercedes & 874 & 1544 & 202 & 785 & 785 & 62 & 5064 \\
\hline Paso de los Libres & 961 & 288 & 169 & 1205 & 386 & 25 & 3644 \\
\hline & 19445 & 16900 & 15627 & 5842 & 18391 & 15528 & 572 & 92305 \\
\hline
\end{tabular}

Fuente: Nueva Época. Corrientes, 13 de marzo de 1946.

\footnotetext{
2 Según algunos estudios de Sociología electoral, en Corrientes, el voto al laborismo está asociado positivamente con la urbanización, obreros, obreros de producción secundaria y de servicios, empleados y profesionales liberales y negativamente con población argentina, analfabeta y cuenta propista. Rasgos que parecen corroborar la distribución de sus votos en los departamentos ya que obtuvo mejores resultados en aquellos con mayor urbanización de la provincia. (Cantón, 1975).
} 
Sin embargo, como el sistema electoral de la provincia era de representación proporcional y se combinaba con una particular división en Secciones Electorales la diferencia entre cada uno de los partidos varía considerablemente al traducirse los votos en escaños. Finalmente, aplicando el sistema de representación proporcional por cuociente correspondieron 5 electores al PDN (DC); la UCR (CN) obtuvo 6 electores, el Antipersonalismo obtuvo 1 elector, el Partido Liberal obtuvo 4 electores; el Autonomismo 2 electores, el Laborista 4 electores y la UCR (JR) 4 electores, mientras que los comunistasPDP no obtuvieron representación en el Colegio Electoral.

Según puede observarse en la Tabla $\mathrm{N}^{\circ} 2$, la combinación de la distribución de los departamentos en las secciones con la aplicación de la fórmula del cociente y residuo dio lugar a que el Partido Laborista que en la primera sección obtuvo el 26, $8 \%$ de los votos consiguiera sólo 2 electores, es decir el mismo número que la UCR que obtuvo el $18,1 \%$ de los votos en esa sección. Además, el Autonomismo con el 5,48\% de los votos obtuvo 1 elector, lo mismo que consiguió la UCR (JR) que había obtenido 16,66\% de los sufragios en esa sección. En la segunda sección, en cambio, el PDN con el 16,9 \% de los votos le pudo alcanzar 2 electores (los mismos que había conseguido el laborismo con un porcentaje mayor en la primera sección). Además, el Partido Liberal con el 16,9\% del total de los votos obtuvo sólo 4 electores, uno menos que el PDN (Ctes) que había alcanzado el 14,8\%, y el Partido Laborista con el 19,9\% de los votos sólo consiguió 4 electores mientras que la UCR con el $16,8 \%$ de los votos obtuvo 6. El Partido Autonomista y el Antipersonalista con el mismo porcentaje de votos obtuvieron diferente cantidad de electores 1 el antipersonalismo y 2 los autonomistas. Por tanto, la aplicación del sistema de representación proporcional y la distribución de las secciones electorales afectaba directamente los resultados de los comicios.

Tabla $N^{\circ}$ 2. Electores de Gobernador y Vice por partidos políticos y por sección electoral

\begin{tabular}{|c|c|c|c|c|c|c|c|}
\hline & PDN (DC) & ANTIP. & PDN (AUT) & LIBERAL & UCR & LABORISTA & UCR (JR) \\
\hline 1era & 1 & - & 1 & 1 & 2 & 2 & 1 \\
Sección & 5444 & 2332 & 2449 & 6578 & 8092 & 12004 & 7450 \\
& $12,18 \%$ & $5,21 \%$ & $5,48 \%$ & $14,7 \%$ & $18,1 \%$ & $26,8 \%$ & $16,66 \%$ \\
& & & & & & & \\
\hline 2da & 2 & 1 & - & 1 & 2 & 1 & 2 \\
Sección & 3561 & 1961 & 1126 & 3340 & 3951 & 3186 & 3808 \\
& $16,9 \%$ & $9,3 \%$ & $5,3 \%$ & $15,9 \%$ & $18,77 \%$ & $15,14 \%$ & $18,09 \%$ \\
& & & & & & & \\
\hline 3era & 2 & - & 1 & 2 & 2 & 1 & 1 \\
Sección & 4655 & 1492 & 2267 & 5709 & 4857 & 3201 & 4270 \\
& $17,5 \%$ & $5,61 \%$ & $8,5 \%$ & $21,5 \%$ & $18,3 \%$ & $12,04 \%$ & $16,06 \%$ \\
& & & & & & & 4 \\
\hline TOTAL & $\mathbf{5}$ & $\mathbf{1}$ & $\mathbf{2}$ & $\mathbf{4}$ & $\mathbf{6}$ & $\mathbf{4}$ & $\mathbf{4}$ \\
& 13660 & 5785 & 5842 & 15627 & 16900 & 18391 & 15528 \\
& $14,8 \%$ & $6,3 \%$ & $6,3 \%$ & $16,9 \%$ & $18,3 \%$ & $19,9 \%$ & $16,8 \%$ \\
& & & & & & & \\
\hline
\end{tabular}

Elaboración propia en base a datos obtenidos en Nueva Época. Corrientes, 13 de marzo de 1946 
La reunión del Colegio Electoral se realizó el 9 de mayo con la presencia de todos los electores. Se eligieron las autoridades y se decidió pasar a un cuarto intermedio hasta el otro día en el que volvió a reunirse aunque, esta vez, con la ausencia del sector peronista. Se inició la votación con los presentes pero, al no conseguirse la mayoría necesaria para consagrar al gobernador, debieron realizarse varias reuniones en días sucesivos. Mientras, paralelamente, los dirigentes partidarios negociaban alianzas. Finalmente, el 15 de mayo, la totalidad de los electores presentes (radicales, demócratas, antipersonalistas, liberales y autonomistas) votaron por la fórmula radical compuesta por Blas Benjamín de la Vega y Justo P. Villar (Solís Carnicer, 2007 a).

El partido Laborista y la UCR (JR) elevaron telegramas al Ministerio del Interior cuestionando la legalidad de la elección, a lo que el General Felipe Urdapilleta respondió que aunque reconocía las falencias del sistema electoral de Corrientes, la elección del gobernador se había realizando siguiendo las normas constitucionales de la provincia, dado lo cual, debían aceptarse los resultados. ${ }^{3}$

De ese modo, el radicalismo accedió por primera vez al gobierno de Corrientes, experiencia que se prolongó por un corto período de un año y tres meses pues, en septiembre de 1947 y tras múltiples tratativas por parte del peronismo, el Congreso Nacional sancionó una ley de Intervención Federal a los tres poderes de la provincia, asumiendo el cargo de interventor el ex jefe de la Policía Federal, el General Juan Filomeno Velazco.

Transcurrido un año, en octubre de 1948, el Ministerio del Interior envió instrucciones al interventor en Corrientes para que inicie el proceso electoral que se llevaría a cabo el 5 de diciembre. En dichos comicios se debían elegir Convencionales Constituyentes Nacionales, Electores a gobernador y Vice de la provincia, Senadores y Diputados provinciales.

Se presentaron a la competencia electoral sólo tres partidos: el peronista, el radical y el PDN unificado (los liberales, los antipersonalistas y los comunistas se abstuvieron de participar instando a sus afiliados por el voto en Blanco). El Partido Peronista proclamó la fórmula Juan Filomeno Velazco- Fernando Irastorza (médico de Curuzú Cuatiá) como candidatos para gobernador y vice aprobados por el Consejo Superior Ejecutivo reunido a ese efecto el 18 de octubre de $1948^{4}$. Los radicales presentaron la suya compuesta por Héctor Lomónaco y Cándido Quiroz ${ }^{5}$ y los Demócratas, luego de amplias deliberaciones y de una reñida votación, decidieron participar en las elecciones llevando como candidatos a Gobernador y Vice a Luis F. Bobbio y Pedro G. de la Fuente. En noviembre se inició la campaña política con una gira proselitista por parte de los candidatos por todo el interior de la provincia y caravanas y mitines en la capital. Tanto el interventor del partido como el periódico peronista vaticinaban un amplio triunfo de su partido con un cálculo de 60.000 votos. ${ }^{6}$

\footnotetext{
${ }^{3}$ La Provincia. Paso de los Libres (Corrientes) 24 de mayo de 1946. p 1

${ }^{4}$ El Liberal. Corrientes, 21 de octubre de 1948. p 4.

${ }^{5}$ El Liberal. Corrientes, 2 de noviembre de 1948 . p 4.

${ }^{6}$ El Diario del Foro. (En adelante DF )Corrientes, 28 de octubre de 1948. p 4.
} 
El total de los electores habilitados para votar en toda la provincia era de 136.107 distribuidos en 698 mesas electorales. El porcentaje total de votantes fue de 61, 9\%, seguramente vinculado con la abstención que habían decidido algunos partidos 7 . En total, 22.724 ciudadanos no cumplieron con la obligatoriedad de votar, situación por la cual la Secretaría de la Junta Escrutadora Nacional elevó al Procurador Fiscal Federal la nómina de todos ellos a fin de que se les acuse de contraventores a la ley electoral. ${ }^{8}$

Los resultados electorales dieron un amplio triunfo al peronismo que obtuvo 51.595 votos, mientras que el radicalismo consiguió 22.935 y el Partido Demócrata Nacional sólo alcanzó 9.764 sufragios. Hubo, además, 2459 votos en blanco y 334 anulados (Véase Tabla $\mathrm{N}^{\circ} 3$ ). Traducidos los votos en escaños, según el sistema de lista completa aplicado en esta oportunidad, correspondieron al peronismo la totalidad de los 32 electores que conformaban el nuevo Colegio Electoral, ganando en todos los departamentos y por lo tanto en las 4 secciones en las que se dividió a la provincia para estas elecciones. El Colegio electoral se reunió el 18 de diciembre y proclamó por unanimidad a la fórmula Velazco - Irastorza como gobernador y vice de la provincia.

Ambas elecciones se realizaron bajo la organización y vigilancia de una Intervención Federal (la de 1946 enviada por el gobierno producto de la Revolución de 1943, y la de 1948, la sancionada por el Congreso nacional en 1947).

Sin embargo, el categórico triunfo del peronismo en ésta última revela la existencia de cambios importantes entre una y otra elección que van desde la reforma del sistema electoral provincial a transformaciones internas dentro del peronismo combinadas con estrategias políticas y electorales claramente direccionadas con el propósito del triunfo. En los dos casos la prensa se mostró conforme con el desarrollo de los comicios, coincidiendo en calificarlos como tranquilos y serenos.

En ambas existió una verdadera competencia electoral, aunque en la elección de 1946 esta fue mayor con la presentación de siete fórmulas gubernativas y ocho partidos políticos, puesto que la aplicación del sistema de representación proporcional favorecía esta división dado que no hacía falta conseguir muchos votos para alcanzar la representación en el Colegio Electoral, bastando con concentrar los suficientes en determinados departamentos. En las elecciones de 1948, que también fueron competitivas, sólo se presentaron tres partidos y fórmulas ya que el establecimiento de un sistema de lista completa requería la unidad de los partidos para conseguir la concentración del mayor número de votos posible.

En las elecciones de 1948, además, el peronismo incrementó su electorado en un $52,11 \%$ en relación a la elección de 1946 y aunque triunfó en todos los departamentos, disminuyó el número de electores en Goya, Ituzaingó y Saladas, en los tres casos como resultado de conflictos internos dentro del partido. El radicalismo, aunque no pudo

\footnotetext{
${ }^{7}$ Es importante aclarar que en todo el país se vivió una reducción importante de votantes en estas elecciones, aunque en el caso de Corrientes resulta más llamativo por tratarse de una elección a gobernador que generalmente resulta de mayor interés para el electorado. Cantón, 1975.

${ }^{8} D F$. Corrientes, 7 de febrero de 1949. p 3.
} 
imponerse en ningún departamento también reflejó un importante incremento en su electorado (35,71\% en relación a la elección de 1946), solo disminuyendo el número de votos con respecto a la elección de 1946 en Itatí, Esquina, Berón de Astrada e Ituzaingó. El partido Demócrata, por su parte, evidenció una pérdida importante de votos en todos los departamentos de la provincia, obteniendo, en conjunto, un $61,39 \%$ menos votos que en la elección de 1946.

Tabla $N^{\circ}$ 3. Resultados electorales 1948

\begin{tabular}{|l|r|r|r|r|}
\hline & Peronismo & UCR & Demócratas & TOTAL \\
\hline Capital & 10680 & 2731 & 1405 & 14816 \\
\hline Empedrado & 1825 & 717 & 684 & 3226 \\
\hline Iratí & 592 & 186 & 178 & 956 \\
\hline San Cosme & 1130 & 299 & 379 & 1808 \\
\hline San Luis del Palmar & 1882 & 436 & 915 & 3233 \\
\hline Bella Vista & 1937 & 1415 & 256 & 3608 \\
\hline Esquina & 2586 & 1134 & 430 & 4150 \\
\hline Goya & 3935 & 3633 & 420 & 7988 \\
\hline Lavalle & 2186 & 1247 & 273 & 3706 \\
\hline San Roque & 1521 & 947 & 453 & 2921 \\
\hline Sauce & 1337 & 345 & 114 & 1796 \\
\hline Berón de Astrada & 293 & 87 & 86 & 466 \\
\hline Concepción & 1341 & 864 & 271 & 2476 \\
\hline General Paz & 2102 & 647 & 311 & 3060 \\
\hline Ituzaingó & 240 & 50 & 28 & 318 \\
\hline Mburucuyá & 1188 & 567 & 332 & 2087 \\
\hline Saladas & 1208 & 1059 & 600 & 2867 \\
\hline San Miguel & 943 & 236 & 240 & 1419 \\
\hline Santo Tomé & 2145 & 1262 & 104 & 3511 \\
\hline Curuzú Cuatí́ & 3336 & 1037 & 932 & 5305 \\
\hline Mercedes & 2335 & 1372 & 502 & 4209 \\
\hline Monte Caseros & 2629 & 593 & 190 & 3412 \\
\hline Paso de los Libres & 1024 & 351 & 3487 \\
\hline San Martín & 1047 & 310 & 3469 \\
\hline TOTAL & 22935 & 9764 & 84294 \\
\hline
\end{tabular}

Fuente: El Liberal. Corrientes, 14 de diciembre de 1948. p 4.

Esta situación refleja con claridad el pasaje de votos de los partidos conservadores hacia el peronismo, tanto de los autonomistas como de los liberales puesto que, aunque 
estos últimos se abstuvieron de participar, el incremento de los votos peronistas en departamentos con una clara y larga tradición liberal así lo refleja (En Mercedes, por ejemplo, donde los liberales habían obtenido la mayoría en las elecciones de 1946, el peronismo obtuvo casi un 50\% más de votos en 1948 con respecto a la elección anterior, en Lavalle y Concepción obtuvo 3 veces más votos que en 1946 y en San Roque un poco más del doble.)

En los apartados que siguen profundizaremos el análisis de los dos aspectos que consideramos fundamentales para entender el triunfo del peronismo en 1948: la reforma del Sistema Electoral y la organización del partido peronista.

Tabla N4. Resumen de los resultados de las elecciones de 1946 y 1948

\begin{tabular}{|l|c|c|c|c|c|c|c|c|}
\hline & $\begin{array}{c}\text { PDN } \\
\text { (Ctes) }\end{array}$ & UCR & ANTIPER & LIBERAL & PDN(Aut) & LABORISTA & UCR (JR) & PERONISTA \\
\hline $\mathbf{1 9 4 6}$ & 13660 & 16900 & 5785 & 15627 & 5842 & 18391 & 15528 & (suma 33919) \\
\hline $\mathbf{1 9 4 8}$ & 9764 & 22935 & & & & & & 51595 \\
\hline
\end{tabular}

\section{II- El Sistema electoral en Corrientes y los resultados electorales}

Los sistemas electorales expresan el modo en que un elector manifiesta, a través del voto, el partido o candidato de su preferencia y la forma según la cual esos votos se convierten en escaños. A su vez, regulan ese proceso mediante la distribución de circunscripciones electorales, la forma de la candidatura y los procesos de votación (Nohlen, 1995).

El sistema que reguló las elecciones provinciales de 1946 fue el de representación proporcional por cuociente que estaba vigente en la provincia desde $1889^{9}$. En cuanto a la distribución en circunscripciones electorales, la ley de 1915 había determinado la división en tres secciones en las que se distribuían los 24 departamentos que conformaban la provincia. Es importante resaltar que esta distribución no respondía a criterios geográficos o demográficos $\mathrm{y}$, aunque podrían presumirse intereses políticos que la fundamentaban, el haberse mantenido su distribución casi sin modificaciones desde 1895 morigera la idea de una intencionalidad política manifiesta hacia mediados del siglo XX. (Véase Mapa $\mathrm{N}^{\circ} 2$ )

La ley electoral de 1915 estableció la siguiente distribución de los departamentos para las elecciones gubernativas y de diputados provinciales:

- 1era: Capital, Empedrado, Bella Vista, Esquina, Monte Caseros, San Martín, Ituzaingó y Goya.

\footnotetext{
${ }^{9}$ El cociente se obtenía dividiendo la cifra total de votos de cada sección por el número de bancas a cubrir. Una vez obtenido el cuociente, la suma total de votos de cada una de las listas se dividía por el mismo cuociente electoral para determinar el número de bancas que correspondía a cada una; mientras que las bancas sobrantes se repartían entre la/s lista/s que hubieran obtenido el mayor residuo. Luego de este procedimiento, la designación de los electos se hacía por sorteo entre todos los integrantes de la misma.
} 
Solís Carnicer. El peronismo en Corrientes. Derrota electoral y conquista del poder político

- 2da: Berón de Astrada, General Paz, Concepción, San Roque, Curuzú Cuatiá, Sauce y Santo Tomé.

- 3era: San Cosme, San Luis, Itatí, San Miguel, Mburucuyá, Saladas, Lavalle, Mercedes y Paso de los libres.

Tanto la categoría de diputados como la de gobernador y vice se elegían por un mismo distrito electoral y la misma cantidad de escaños, que difería para el caso de los senadores. La magnitud o tamaño de estas circunscripciones, es decir, la cantidad de escaños que debía elegirse en cada una de ellas, no era uniforme. En el caso de la Cámara de Diputados, ocho miembros correspondían a la primera sección y nueve a la segunda y tercera (igual distribución correspondía al Colegio Electoral). El sistema se completaba a través del sufragio obligatorio, secreto, individual y directo y el establecimiento de boletas cerradas $^{10}$

La elección del gobernador era indirecta. Y en el caso del Colegio Electoral de Corrientes que se componía (al igual que la Cámara de diputados) de 26 electores, hacían falta 14 (es decir la mitad más uno) para designar al gobernador. Esta situación hacía difícil que un sólo partido lograra obtenerlos, por lo que imperiosamente debían reunirse varios, es decir, hacer acuerdos o pactos. Cosa que ocurrió constantemente en la historia política provincial y también fue el caso de la elección de 1946, en la que producto de un acuerdo post- electoral el radicalismo consiguió imponer su fórmula gubernativa.

Esta situación había generado críticas constantes por parte de los partidos políticos que se sentían perjudicados por el sistema electoral. Así ocurrió con el radicalismo durante la denominada etapa radical entre 1916 y 1930 y, en esta oportunidad, con el peronismo, constituyendo este tema uno de los principales argumentos para la Intervención Federal de 1947.

En 1948, el mismo Ministro del Interior fue el encargado de comunicar que, luego de haberse estudiado en profundidad la ley electoral de Corrientes y la distribución en secciones electorales, se habían tomado medidas para que las reformas propuestas estuvieran en consonancia con la Constitución Nacional y Provincial ${ }^{11}$. Se realizó una nueva distribución de las secciones electorales contemplando los criterios geográficos, demográficos y económicos buscando una mayor proporcionalidad en el número de habitantes entre cada sección y su representación en el Colegio Electoral. Se decidió, asimismo que la división en secciones sería la misma para todas las elecciones, agregándose una sección más. (Véase Mapa $\mathrm{N}^{\circ}$ 3)

La nueva distribución de los departamentos en las secciones electorales quedó de la siguiente manera:

- 1era: Capital, Empedrado, Itatí, San Cosme y San Luis del Palmar. (7 electores de gobernador)

\footnotetext{
${ }^{10}$ El sistema electoral provincial y sus implicancias políticas fue analizado en Solís Carnicer y Sternberg, 2004.

${ }^{11} \mathrm{DF}$. Corrientes, 28 de octubre de 1948. p 5.
} 
- 2da: Bella Vista, San Roque, Lavalle, Goya, Esquina, Sauce (10 electores de Gobernador)

- 3era: Berón de Astrada, San Miguel, Ituzaingó, Santo Tomé, Concepción, Saladas, Mburucuyá y General Paz (6 electores de gobernador)

- 4ta: Mercedes, Curuzú Cuatiá, Monte Caseros, Paso de los Libres, San Martín. (9 electores de gobernador)Se aumentó el número de diputados y senadores provinciales en función de los resultados del censo de 1947 estableciéndose, entonces, que la distribución de los legisladores se haría en base a un cálculo matemático sobre un cuociente de 17.843 habitantes para diputados y de 35.685 para senadores. A partir de ese momento, los diputados serían 32 y no 26 y los senadores, 16 y no 13.

Al mismo tiempo se estableció que el sistema electoral que se aplicaría en las elecciones sería el correspondiente a la ley nacional que establecía la representación de mayoría y minoría en las elecciones legislativas y de lista completa en las ejecutivas.

La primera sección con 129.298 habitantes elegiría 7 diputados, 5 por la mayoría y 2 por la minoría y 4 senadores, 3 por la mayoría y 1 por la minoría. La segunda sección con 172.719 habitantes elegiría 10 diputados, 7 por la mayoría y tres por la minoría, y 5 senadores, 4 y 1.La tercera sección con 113.173 habitantes elegiría 6 diputados 4y 2, y 3 senadores 2 y 1 . La cuarta sección con 155.777 habitantes elegiría 9 diputados, 6 y 3 , y 4 senadores, 3 y 1 . En total se elegirían 22 diputados por la mayoría, y 10 por la minoría, y 12 senadores por la mayoría y 4 por la minoría. ${ }^{12}$

Inmediatamente se hicieron sentir algunas voces opositoras a estas reformas, apoyadas en el art. 35 de la Constitución provincial que establecía el sistema de representación proporcional para todas las elecciones provinciales ${ }^{13}$, principio que aquí no se respetaba.

Tabla $N^{\circ}$ 5. Sistema electoral aplicado en las elecciones ejecutivas de 1946 y de 1948

\begin{tabular}{|l|l|l|}
\hline & $\mathbf{1 9 4 6}$ & $\mathbf{1 9 4 8}$ \\
\hline Sistema electoral & $\begin{array}{l}\text { Representación proporcional por } \\
\text { cuociente } \\
\text { Elección Indirecta del gobernador }\end{array}$ & Lista completa \\
Elección indirecta del Gobernador. \\
\hline $\begin{array}{l}\text { Secciones electorales } \\
\text { plurinominales }\end{array}$ & $\begin{array}{l}\text { Departamentos distribuidos en 3 } \\
\text { secciones electorales sin un criterio } \\
\text { demográfico o geográfico }\end{array}$ & $\begin{array}{l}\text { Departamentos distribuidos en } \\
\text { 4 secciones electorales según un } \\
\text { criterio demográfico y geográfico }\end{array}$ \\
\hline Colegio Electoral & 26 miembros & 32 miembros \\
\hline
\end{tabular}

${ }^{12}$ El Liberal. Corrientes, 19 de octubre de 1948. p 4.

${ }^{13}$ El Liberal. 22 de octubre de 1948. p 4 
Las críticas a la aplicación del sistema de representación proporcional combinado con la elección indirecta del gobernador y la división en secciones electorales eran ya históricas en la provincia de Corrientes, sin embargo no hubo, hasta 1946, intentos claros orientados hacia su reforma (que implicaba la reforma de la Constitución Provincial). Una situación similar a la ocurrida en el Colegio Electoral de 1946 había sucedido en 1919 en la que, con el propósito de impedir el triunfo radical, los conservadores se unieron para votar al partido que menos electores había obtenido en esa elección (Solís Carnicer, 2005). En esa oportunidad habían sido los radicales los que protestaron por lo que consideraron un triunfo ilegítimo, situación que, sin embargo, en 1946 aceptaron como válida, siendo entonces los peronistas los que elevaron las protestas. Pero el contexto político e ideológico de 1946 era ya muy distinto al anterior, los cuestionamientos al sistema eran compartidos por todas las fuerzas políticas, llegándose incluso a aprobar una ley de reforma de la constitución que no pudo llevarse a cabo debido a la llegada de la intervención federal. Además, el sistema, cuya aplicación había sido tan favorable a los partidos conservadores provinciales, ya mostraba signos claros de agotamiento. $\mathrm{La}$ aparición de una fuerza política nueva con una importante capacidad de movilización electoral erosionaba sus bases y cuestionaba sus fundamentos. Por eso, en el momento en el que el Ministerio del Interior decidió reformar el sistema por medio de un decreto, las únicas críticas que se esbozaron fueron relativas a su inconstitucionalidad, pero no al contenido mismo de las reformas sobre las que ya existían ciertos acuerdos implícitos.

\section{III- El partido peronista en Corrientes. La organización de su estructura partidaria y la definición de sus rasgos identitarios}

Además de las reformas en el sistema electoral, consideramos que otro de los factores de peso en los resultados electorales de 1948 fue la reorganización del peronismo, tanto desde el punto de vista de su estructura partidaria como de los rasgos de su identidad. Según Angelo Panebianco, las peculiaridades del período de formación de un partido, los rasgos en que se refleja su gestación, ejercen influencia sobre sus características organizativas. Toda organización lleva sobre sí la huella de las peculiaridades que se dieron en su formación y de las decisiones político-administrativas más importantes adoptadas por su fundadores (Panebianco, 1982). De ahí la importancia de su estudio para entender sus rasgos y peculiaridades.

En las elecciones de 1946, el peronismo, que hacía pocos meses había iniciado su configuración, se presentó repartido en dos partidos, por un lado el Laborismo y por otro, la UCR (JR) y aunque ambos llevaban a Santiago Ballejos como candidato a Vice gobernador no pudieron ponerse de acuerdo en quién debía encabezar la fórmula.

La UCR (JR) se conformó a partir de mediados de 1945 a iniciativa de Hortensio Quijano, que en ese momento ocupaba el cargo de Ministro del Interior. Quijano era un antiguo dirigente del radicalismo correntino que, aunque no había tenido una actividad política relevante tenía cierto predicamento en el seno del partido. Aunque en ese momento formaba parte de la UCR $(\mathrm{CN})$ de la que luego fue expulsado, en su trayectoria 
política anterior siempre se había mostrado más cerca de los sectores antiyrigoyenistas del partido. A partir de la figura de Quijano y del interventor Ernesto Bavio (un radical salteño nombrado interventor en Corrientes en 1945), se empezó a organizar en la provincia el grupo radical que apoyaría la candidatura de Perón, consiguiendo armar este nuevo partido que se denominó en un primer momento UCR (Junta Reorganizadora) y que luego pasó a llamarse UCR (Junta Renovadora). Quienes lo constituyeron fueron, en general, radicales con algún tipo de participación política previa; no se trató de recién llegados sino de dirigentes con cierta trayectoria en el seno del radicalismo (tanto personalista como antipersonalista)

En cuanto al Laborismo, después de un intenso trabajo iniciado a partir de la Delegación de la Secretaría de Trabajo y Previsión, especialmente a partir de la gestión del capitán José Ramón Virasoro, a fines de agosto de 1945, quedó constituida la Confederación General de Obreros Correntinos. Con esa base institucional se constituyó a mediados de noviembre de 1945 el Partido Laborista ${ }^{14}$. El 21 de noviembre, realizó en Corrientes una reunión en la que se elaboró un programa de acción mínima y la carta orgánica del partido que fue aprobada en asamblea. Posteriormente, se designó la Junta Ejecutiva ocupando la presidencia Juan Mihovilcevich, un dirigente sindical que pertenecía al gremio de los portuarios. ${ }^{15}$ Los que se adhirieron a este nuevo partido fueron, en general, trabajadores, sindicalistas o jóvenes sin antecedentes en la actividad política provincial. En un primer momento recibieron el apoyo de los jóvenes nacionalistas de la Alianza Libertadora quienes colaboraron activamente con el Laborismo en las elecciones de 1946 (Solís Carnicer, 2008).

Tras el fracaso electoral del peronismo en las elecciones provinciales de febrero de ese año, el laborismo ingresó en un período de crisis interna que se pronunciaría Perón al decidir, en mayo, disolver a los dos partidos políticos que lo habían apoyado en las elecciones y constituir el Partido Único de la Revolución. En respuesta a esa iniciativa un sector del Laborismo liderado por José Ramón Virasoro organizó el Partido Laborista Correntino, expresando que no estaba en contra de la unidad del peronismo pero que quería defenderlo de los oportunistas que veía acercarse al movimiento. ${ }^{16}$

En enero de 1947, Perón aceptó que a partir de ese momento se llamara Peronista al Partido Único de la Revolución, dejando con ello solucionadas algunas de las diferencias surgidas entre las fracciones del movimiento ${ }^{17}$. A fines de enero, entonces, se realizó en la capital de la provincia un Congreso del Partido Laborista Correntino, con asistencia de los miembros de la Junta Ejecutiva Provisional presidida por José Ramón Virasoro y los delegados departamentales. En esa reunión se dio por extinguido al partido y se aprobó

\footnotetext{
${ }^{14}$ Nueva Época. Corrientes, 17 de noviembre de 1945. p. 1.

${ }^{15}$ Los demás miembros fueron Vicente Cocchia como vicepresidente 1, Jorge Waldino Contreras como vice presidente 2, Alberto Fernández, secretario general, Juan Jorge Zamparalo, secretario de actas, José Dionisio Virasoro secretario del interior, Sabino Acota Monzón secretario de Prensa y Propaganda y Juan de la Cruz Solís como tesorero. Todos ellos de un claro origen sindical, en el caso del presidente Juan Mihovilcevich provenía del gremio de los estibadores. El Liberal. Corrientes, 23 de noviembre de 1945. p. 2.

${ }^{16}$ El Liberal. Corrientes, 18 de noviembre de 1946. p 2

${ }^{17}$ La Mañana. Corrientes, 16 de enero de 1947. p 1.
} 
Solís Carnicer. El peronismo en Corrientes. Derrota electoral y conquista del poder político

la organización del peronismo en la provincia incorporándolo al partido nacional. Sin embargo, hacia septiembre de 1947, en las vísperas de la intervención federal, el peronismo aún no había alcanzado una organización definitiva y existían en su seno importantes conflictos de poder: "El partido peronista que está en el embrión de su organización, tiene lógicamente muchas cabezas, que, por su actuación revolucionaria, por sus indudables dotes, están en condiciones de ejercer la presidencia del partido, y en cualquier momento el gobierno de la provincia, de ahí entonces que la simpatía que por determinadas personas existe dentro del partido se tome como una división cuando no es así"18

Una vez instalada la intervención federal, que entre sus principales propósitos tenía el de organizar al peronismo y prepararlo para un triunfo electoral, se inició dicho proceso. El Diputado Nacional Daniel Mendiondo, que provenía de la UCR JR, fue designado presidente de le Junta Provincial pero pronto el partido fue intervenido ocupando ese lugar el también Diputado Nacional Antonio J. Benítez ${ }^{19}$. Bajo su dirección, el 9 de noviembre de 1947, se realizaron las elecciones internas de 18 convencionales partidarios para el Congreso General Constituyente del Partido que tendría a su cargo la tarea de redactar la Carta Orgánica, determinar su nombre definitivo y elegir sus autoridades ${ }^{20}$. Se presentaron dos listas, la "verde" encabezada por Santiago Ballejos que recibió el apoyo de los municipios, de la Federación Obrera Provincial, de la UCR JR, una parte del Laborismo y del gobierno de la Intervención Federal y la "blanca" liderada por José Ramón Virasoro con el apoyo de un sector del laborismo y de la Delegación Regional de la CGT. La lista verde resultó triunfante por amplia mayoría de votos y Virasoro denunció actividades dolosas por parte de funcionarios a favor de la lista verde, expresando que no se habían expuesto los padrones de afiliados y que en varios departamentos se había impedido a sus adherentes el acceso a las mesas receptoras de votos. ${ }^{21}$

Ambos (Virasoro y Ballejos) habían constituido la fórmula electoral por el Laborismo de 1946, Ballejos, además, había sido candidato a vice gobernador por la UCR JR en esa misma oportunidad. Eran dos figuras centrales de ese primer peronismo correntino que en estas elecciones se disputaban la representación del partido. Es decir que, más allá de la elección de convencionales se estaba poniendo en juego el liderazgo de estas dos figuras centrales del peronismo, proceso que representa un papel crucial en el momento en que un partido político se encuentra en una etapa de construcción (Panebianco, 1982). Virasoro, había sido uno de los primeros delegados de la Secretaría de Trabajo y Previsión en Corrientes. Se trataba de un joven militar correntino sin antecedentes en la actividad política, que después del 17 de octubre de 1945, había solicitado su baja del Ejército

\footnotetext{
${ }^{18} \mathrm{DF}$. Corrientes, 1 de septiembre de 1947. p 1.

${ }^{19}$ Había ocupado el cargo de Ministro de Justicia e instrucción Pública de la Nación después de la revolución del 4 de junio, Asesor Letrado de la Policía Federal, Ministro del Superior Tribunal de La Rioja, Presidente de la Caja de Ahorro de la provincia de Tucumán, Prof. Titular de la Cátedra de Derecho de Navegación en la Facultad de Derecho y Ciencias Sociales de Buenos Aires. DF. Corrientes, 28 de octubre de 1948. p 4.

${ }^{20}$ Estas elecciones internas se realizaron en todo el país el 21 de noviembre, Corrientes fue el único distrito en la que se realizaron por adelantado.

${ }^{21}$ El Liberal. Corrientes, 10 de noviembre de 1947. p 2 y La provincia (Paso de los Libres, Corrientes), 14 de noviembre de 1947. p 1.
} 
y se había dedicado a trabajar por la organización del partido laborista en Corrientes. Entre 1944 y 1946 trabó relaciones con dirigentes gremiales locales, organizándolos y ejecutando la política laboral impulsada por el gobierno nacional. Esa situación hizo que, al momento de definirse las candidaturas en 1946, gozara de gran predicamento en las filas del laborismo. Sin embargo, se mostró intransigente para la negociación política, motivo por el cual no fue posible llegar a consagrar una fórmula común con la UCR (JR) (Aguirre, 2002) ${ }^{22}$.

Por otro lado, Santiago Ballejos, que en ese momento ocupaba el cargo de ministro de gobierno de la intervención de Velazco, tampoco provenía del movimiento sindical, aunque había tenido alguna participación en la organización de las luchas de los trabajadores tabacaleros en el campo goyano (Aguirre, 2002). Se trataba de un joven carismático con ambiciones políticas que muy recientemente había iniciado su actividad pública. Defensor de ideas nacionalistas, formaba parte de la Alianza Libertadora y como único antecedente en la actividad administrativa tenía el haber ocupado la intendencia de Goya durante la intervención nacionalista de David Uriburu (1944) ${ }^{23}$.

Las denuncias presentadas por Virasoro fueron desestimadas y, a partir de allí, éste perdió su posición dentro del partido. Se le ofreció un cargo en un cuerpo diplomático en la ciudad de Viena (Austria) que lo alejó definitivamente de la política provincial24. Ballejos se convertía, entonces, en uno de los dirigentes más prometedores del peronismo correntino que tendrá, luego, que disputar ese liderazgo con el mismo Juan Filomeno Velazco.

Es claro que, para ese momento, Virasoro había perdido todo tipo de control sobre las "zonas de incertidumbres" más vitales del partido ${ }^{25} \mathrm{y}$ que, en el juego de intercambio vertical (entre líder y seguidores), no alcanzó a otorgar suficientes incentivos colectivos (identitarios) y selectivos (materiales). Ballejos, funcionario de la intervención, contaba con el apoyo económico de ésta y de la posibilidad de ofrecer mayores incentivos materiales (especialmente cargos) a sus seguidores, Virasoro, que no contaba con esta posibilidad tampoco pudo ofrecer incentivos colectivos fuertes en un momento en que el mismo Perón buscaba diferenciarse del laborismo.

En enero de 1948, se reunió la Convención partidaria que aprobó la carta orgánica y la plataforma para el distrito Corrientes ${ }^{26}$. Ésta, previamente elaborada, fue presentada por el interventor y aprobada sin discusión. Allí mismo surgió la posibilidad de la futura candidatura a gobernador de Santiago Ballejos, que había crecido en popularidad a través del cargo de Ministro de Gobierno, ocupando la intervención por períodos largos de

\footnotetext{
${ }^{22}$ Algunos de estos datos nos brindó el Sr. Carlos Gauna en la entrevista realizada en Corrientes el 18 de abril de 2008.

${ }^{23}$ Universidad Di Tella. Archivo Historia Oral (En adelante AHO) "Entrevista a Joaquín Díaz de Vivar” y Aguirre, 2004.

${ }^{24}$ La Mañana, Corrientes, 27 de enero de 1948. p 3.

${ }^{25}$ Angelo Panebianco considera que los recursos del poder están ligados al control sobre áreas de incertidumbre organizativa, es decir aquellos factores que, de no ser controlados amenazarían o podrían amenazar la supervivencia de la organización y/o la estabilidad de su orden interno

${ }^{26} D F$. Corrientes, 5 de enero de 1948.
} 
tiempo a raíz de los continuos viajes a Buenos Aires por parte del interventor provincial en busca de apoyo económico y financiero. Publicaciones en periódicos vinculados al peronismo y diversas asociaciones gremiales iniciaron una campaña a favor de su candidatura. Esa situación generó rápidamente una competencia interna entre Ballejos y Velazco quien, paralelamente, impulsó la candidatura de Ballejos para las elecciones a Diputados Nacionales de marzo de 1948 con el objeto de alejarlo de la posibilidad de acceder al gobierno de la provincia.

Una nota editorial publicada por un periódico peronista reflejaba con claridad la existencia de divisiones internas dentro del partido y la necesidad de superarlas para evitar futuros inconvenientes y tropiezos en el camino de acceso al gobierno provincial:

"El peronismo correntino debe meterse en la médula una convicción fundamental: sin unidad, las fuerzas más poderosas caen destrozadas por el enemigo. La gran ocasión de superarnos que los peronistas daríamos al enemigo sería que abramos a nuestras filas el cáncer de la discordia. En cambio, la demostración más evidente de nuestra nervadura política de nuestro empuje popular, de nuestro derecho a gobernar y de la realidad de nuestra superioridad indiscutible, es la unidad. Esto es clarísimo y es indiscutible. Por otra parte, las rencillas domésticas darían al Jefe máximo de la revolución, que no transige con maniobras turbias y con miras subalternas, la impresión de que el peronismo de la provincia está deshilachado por ambiciones oscuras y su reprobación caería firme y enérgica sobre nuestra pujanza. Es menester, por lo tanto, sacar telarañas de los ojos para que se aclare la visión y deponer egoísmos para que el sentir cobre vigor incontrastable y sea la unanimidad el formidable impulso del triunfo" ${ }^{27}$.

Finalmente, en febrero de 1948 y después de buscar sin éxito el apoyo de Perón, el ministro Ballejos presentó su renuncia motivada fundamentalmente por estas diferencias con Velazco. Algunos de sus seguidores incitaron a realizar "borratinas" en la lista de candidatos a diputados nacionales en las elecciones de marzo, situación que fue denunciada por el interventor del partido. Esto motivó que Ballejos fuera condenado como traidor al peronismo y a su jefe ${ }^{28}$. En su reemplazo se nombró, en el Ministerio de Gobierno a Héctor Sustaíta Seeber (diputado nacional por Buenos Aires y amigo personal del interventor). De ese modo, Velazco lograba desplazar a Ballejos de la competencia por el liderazgo dentro del partido y se configuraba como único líder del peronismo de Corrientes.

Paralelamente, se hacían tratativas con hombres de los partidos provinciales. El mismo Velazco fue el encargado de realizar las negociaciones con los partidos autonomista

\footnotetext{
${ }^{27} \mathrm{DF}$. Corrientes, 30 de enero de 1948. p 1.

${ }^{28}$ DF. Corrientes, 8 de marzo de 1948 p. 3.
} 
y libera ${ }^{29}$. En un primer momento, buscó el apoyo de sus dirigentes consiguiéndolo sólo parcialmente, y aunque no pudieron cerrar ninguna alianza oficial, consiguió reducir electoralmente al autonomismo y que los liberales decretaran la abstención en todas las elecciones del período, quitándolos del medio en la competencia electoral ${ }^{30}$. Según Joaquín Díaz de Vivar, diputado nacional por el peronismo entre 1946 y 1955, un sector importante del partido liberal, especialmente de la localidad de Esquina, representado por Raimundo Meabe, Mariano Gómez y Erasmo y Benigno Martínez, se volcó al peronismo, no en forma oficial pero sí "vergonzante" pues, aunque en las Convenciones declaraban su oposición, al decretar la abstención y en algunos casos solicitar el voto en Blanco de sus afiliados, colaboraron con el triunfo del peronismo en $1948^{31}$.

En abril de 1948, el interventor del partido comunicó la decisión del Consejo Superior de designar la fórmula gubernativa para Corrientes compuesta por Velazco y Fernando Irastorza, así como también designó a los 32 candidatos a diputados provinciales y 16 candidatos a senadores provinciales ${ }^{32}$. A fines de septiembre, Velazco renunció a su cargo como interventor federal para dedicarse abiertamente a la campaña política. En su lugar fue designado Estanislao de la Torre.

Finalmente, al día siguiente de las elecciones de diciembre, se expulsó del partido a Santiago Ballejos al comprobarse que había aconsejado a los peronistas de Goya votar por los candidatos de la UCR ${ }^{33}$. De ese modo quedó consagrada la figura de Juan Filomeno Velazco, como único líder del partido en Corrientes quien, por su vinculación familiar con dirigentes liberales, por su carácter conservador desde el punto de vista político y económico, admirador del nacionalcatolicismo de carácter integrista, representaba la figura de un dirigente más compatible con la tradición política provincial y por ende podía conseguir más adhesiones y menos rechazos ${ }^{34}$. Además, Velazco era amigo personal de Perón. Como Jefe de la Policía Federal tuvo una importante actuación en la jornada del 17 de octubre, apoyando el desarrollo de dicha movilización, en 1946 dirigió un partido denominado Independiente que se unió a la UCR (JR) y al Laborismo para apoyar la elección de Perón. Antecedentes, todos, que lo ubicaban en un lugar de privilegio en

${ }^{29} \mathrm{DF}$. Corrientes, 16 de febrero de 1948. p 1

${ }^{30} \mathrm{DF}$. Corrientes, 5 de marzo de 1948. p 3

${ }^{31} D F$. Corrientes, 22 de abril de 1948. p 3.

${ }^{32} D F$. Corrientes, 22 de abril de 1948. p 3.

${ }^{33} \mathrm{DF}$. Corrientes, 6 de diciembre de 1948. p 1.

${ }^{34}$ Simpatizante del Eje y amigo personal de Perón, ocupó cargos claves tanto en el gobierno provisional de Uriburu en 1930 en el que se desempeñó como Secretario del Ministerio de Guerra y Jefe de Seguridad de la policía de la Capital Federal, como después de la revolución de 1943, en la que se le encargó la organización de la Policía Federal Argentina, convirtiéndose en jefe de dicha fuerza en 1944. Mientras ocupó el cargo de jefe de policía realizó actividades de espionaje contra los estadounidenses residentes en la Argentina durante la Segunda Guerra Mundial, terminada la guerra prohibió la realización de manifestaciones a favor de los aliados y el 2 de mayo de 1945 protagonizó una dura represión contra un grupo de manifestantes que celebraban el triunfo de los aliados a los que amenazó con darles "confite" (acribillar). Era común escuchar en esa época entre los estudiantes y los manifestantes antifascistas la consigna "Que risa, que asco, la cara de Velazco", fue una pieza clave en la organización del primer peronismo, a través un proceso de "peronización" de las fuerzas policiales. Véase: Andersen, 2002. 
la estructura del peronismo y por ende, su figura y su liderazgo no podían discutirse ${ }^{35}$. En 1947, fue interventor federal en la provincia enviado por Perón y al año siguiente se convirtió en el primer gobernador peronista de Corrientes. El periódico peronista $E l$ Diario del Foro, que durante los meses de la intervención federal había acompañado el proceso de organización partidaria y colaborado abiertamente en la construcción del liderazgo de Velazco, así describió su lugar en el peronismo provincial y nacional:

Y es así como la Nueva Argentina vio nacer en las horas grávidas, junto al líder al "hombre de la lealtad". También a su lado desde las horas primeras de la gestación hubo un "ciudadano de la fidelidad". Este es el título que le corresponde a ese soldado de reciedumbre intangible que se llama J. Filomeno Velazco que con serenidad y firmeza, permitió, protegió y alentó el proceso histórico que nos llevaría al presente luminoso de hoy, dirigidos por el Gran Jefe Juan D. Perón, líder indiscutido. [...]

El general J. Filomeno Velazco, puño de acero de la revolución, espíritu indomable y de la "fidelidad" al General Perón, tiene merecimientos de sobra y legítimamente conquistados para gobernar a Corrientes, provincia que honra al país, y cuyo gobernante la honrará con las luces de su sabiduría y la madurez patriótica de su espíritu eminentemente nacionalista, como el de aquellos a quienes representa con su estampa de relieves puros de indomable argentinidad. ${ }^{36}$

Para ese momento, el partido peronista se personalizaba cada vez más y la verticalidad se exhibía de un modo cada vez más acentuado. Las candidaturas, ya fueran para cargos provinciales o nacionales, eran todas digitadas desde Buenos Aires ${ }^{37}$ y solamente tenían acceso autorizado al círculo interno del partido quienes gozaban del apoyo y la confianza de Perón. En ese contexto, la figura de Velazco se adaptaba con facilidad a los rasgos que iba adquiriendo el partido peronista al tiempo que significaba para Corrientes solo un cambio moderado de sus tradiciones y cultura política que le permitiría iniciar, aunque sin sobresaltos revolucionarios, una nueva etapa de su historia.

\section{Reflexiones finales}

El triunfo del peronismo en Corrientes en las elecciones provinciales de 1948, fue el resultado de un proceso iniciado tras la derrota electoral de 1946. En esa oportunidad se había empezado a transitar un camino diferente en la historia política provincial por

\footnotetext{
${ }^{35}$ Datos obtenidos de Raúl Héctor Barrios. Vida y Obra del General Juan Filomeno Velazco. Esquina (Corrientes), S/F, Inédito; Pont, 1984 y AHO. Entrevista a Joaquín Díaz de Vivar.

${ }^{36} \mathrm{DF}$. Corrientes, 4 de marzo de 1949. p 4.

${ }^{37}$ Con esas palabras se expresó Joaquín Díaz de Vivar. En: AHO “Entrevista a Joaquín Díaz de Vivar”. Otros ejemplos, incluso sobre su propia candidatura a diputado provincial, nos comentó Melitón Aguirre en la entrevista que le realizamos en Corrientes el 6 de marzo de 2008.
} 
primera vez los partidos conservadores no conseguían llegar al gobierno de la provincia y ese lugar era ocupado por los radicales, que hasta entonces habían sido sus principales adversarios pero que, sin embargo, llegaban al poder con el apoyo de los electores conservadores.

Tras la derrota, el peronismo debió redefinir sus estrategias políticas y electorales, para ello, la intervención federal a la provincia, sancionada en septiembre de 1947, constituía un eslabón fundamental. A partir de allí, inició un doble proceso de cambios, externo por un lado, a través de una reforma del sistema electoral buscando la construcción de un diseño institucional que facilitara su triunfo y por otro, interno, que se proponía la organización del partido en Corrientes de modo de llegar fortalecido a la lucha electoral.

El sistema de representación proporcional por cuociente, combinado con una particular división en secciones electorales, y la elección indirecta del gobernador, que estaba vigente desde fines del siglo XIX, había favorecido la supervivencia de los partidos conservadores y su permanencia en el gobierno provincial. Por ese motivo, el sistema había sido objeto de cuestionamientos por parte de los radicales, pero no se lo había cambiado puesto que, para ello, hacía falta una reforma de la Constitución provincial, hecho al que los conservadores se opusieron tenazmente, ya que este sistema, al mismo tiempo que los favorecía, no impedía la participación competitiva de otras fuerzas y su representación en el Colegio Electoral y en la Legislatura de la provincia.

La influencia del sistema en los resultados electorales puede observarse con claridad en las elecciones de 1946 en las que la traducción de los votos en escaños generó cierta distorsión con respecto a los resultados genuinos de la elección. La situación vivida posteriormente en el Colegio Electoral y la decisión adoptada por los partidos conservadores de votar por la fórmula radical constituyó un punto de inflexión que derivó en un consenso acerca de la necesidad de la reforma del sistema por parte de todos los actores políticos involucrados $\mathrm{y}$, al mismo tiempo, fue uno de los principales argumentos esgrimidos por los peronistas para conseguir la intervención federal. Por ese motivo, quizás, la decisión de reformarlo a través de un decreto no generó oposiciones fuertes. Salvo algunas voces que tímidamente demostraron su disconformidad por su carácter inconstitucional, no se escucharon grandes cuestionamientos a la medida.

De ese modo, el peronismo conseguía lo que durante décadas el radicalismo había buscado sin éxito: la reforma del sistema electoral provincial, el reemplazo del sistema de representación proporcional por el de lista completa y una nueva distribución de las secciones electorales. El marco institucional que permitiría el triunfo del peronismo estaba en marcha.

Sin embargo, sólo con una reforma del sistema electoral no bastaba para conseguir ese triunfo; hacía falta aún superar otros obstáculos, organizar al partido, eliminar las divisiones internas y los liderazgos conflictivos, con el objeto de buscar la unidad y la definición de rasgos identitarios fuertes capaces de fortalecer los lazos entre los seguidores.

En primer término y con un partido intervenido por el Consejo Superior, se buscó disminuir el papel del sindicalismo alejando a sus más destacados referentes de 
los principales espacios de poder. Paralelamente, se buscó la concentración del liderazgo, separando a aquellos dirigentes con dificultades para subordinarse a un estilo verticalista. Juan Filomeno Velazco cumplió con esos requisitos y consiguió imponerse como líder indiscutido del peronismo provincial. Su figura, al mismo tiempo que representaba una adhesión incondicional a Perón, no rompía con los rasgos de la tradición conservadora de la política provincial, lo que le permitió al peronismo recibir apoyos de sectores conservadores, tanto del autonomismo como del liberalismo, que se tradujeron en un importante número de votos que colaboraron con su triunfo en 1948.

\section{MAPA No 1}

Secciones Electorales para diputados y electores de Gobernador y Vice-Goberndor Año 1915

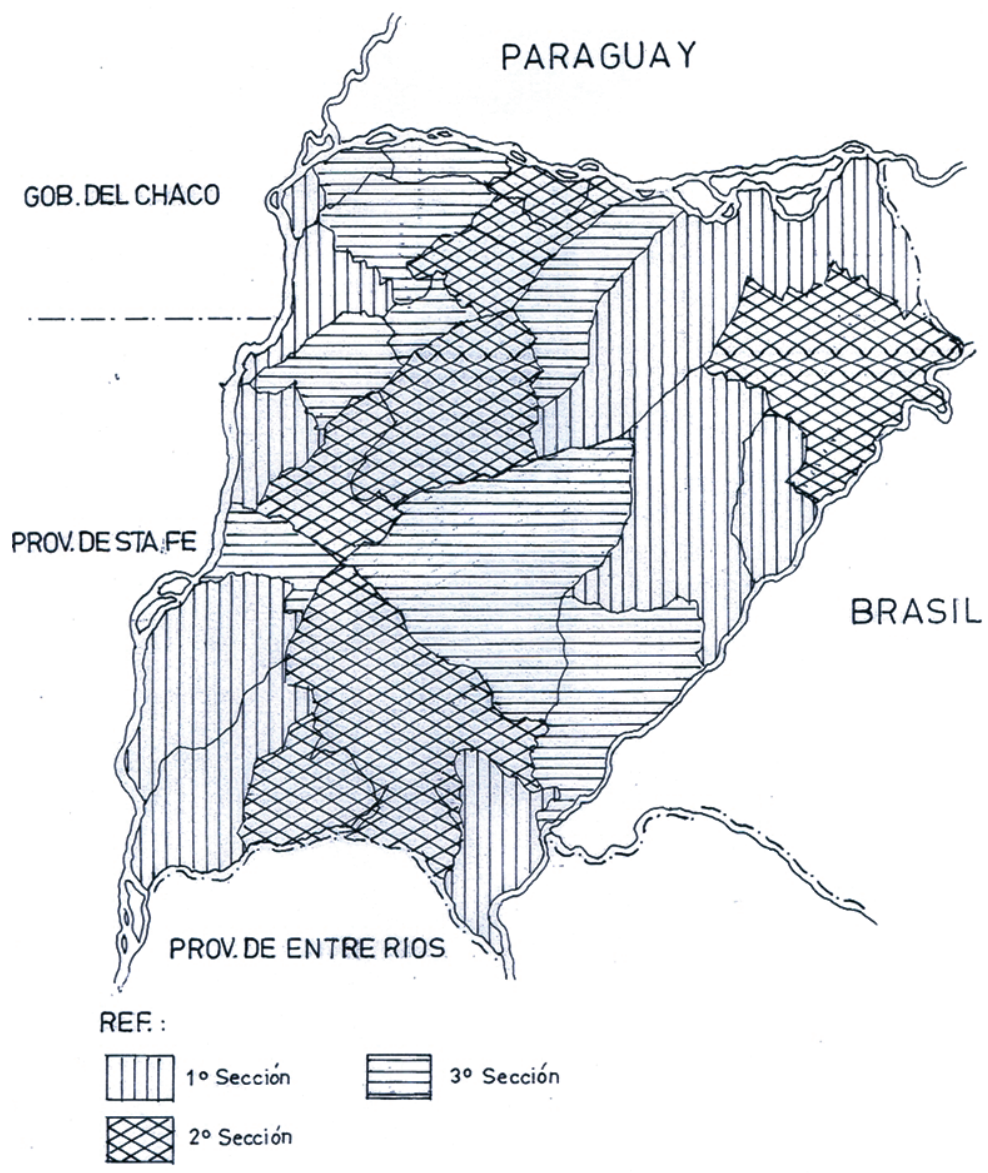

Fuente: Gómez Hernán. Jurisdicciones territoriales. [Atlas de la provincia de Corriente, geográfico y político]. Buenos Aires, 1936 y electoral de la provincia de Corrientes. Año 1915 
Esta situación confirma, una vez más, las interpretaciones sobre los orígenes del peronismo en el interior del país, donde se produjo la invención de una tradición de mezcla que, presentándose como una nueva matriz para pensar la sociedad y la nación, modificaba el sentido de las diferentes tradiciones que tomaba como insumo para construir una nueva representación colectiva (Macor y Tcach, 2003). Con un peronismo organizado $\mathrm{y}$ fortalecido por la unidad y un diseño institucional propicio estaba allanado el camino que lo llevaría al triunfo

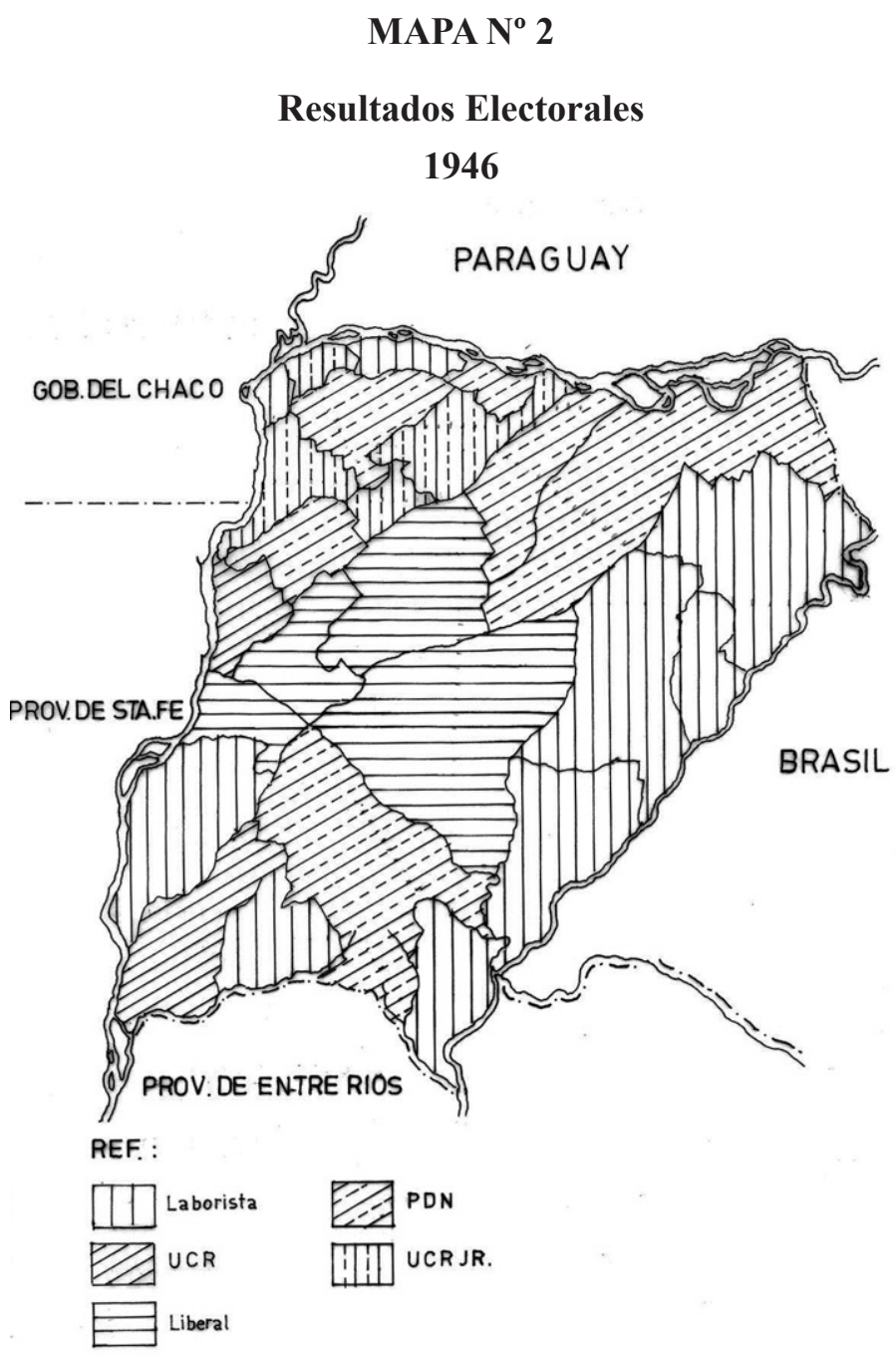

Fuente: Gómez Hernán. Jurisdicciones territoriales. [Atlas de la provincia de Corriente, geográfico y político]. Buenos Aires, 1936 y Nueva Epoca. Corrientes, 13 de marzo de 1946. 


\section{MAPA N 3 \\ Secciones Electorales}

1948

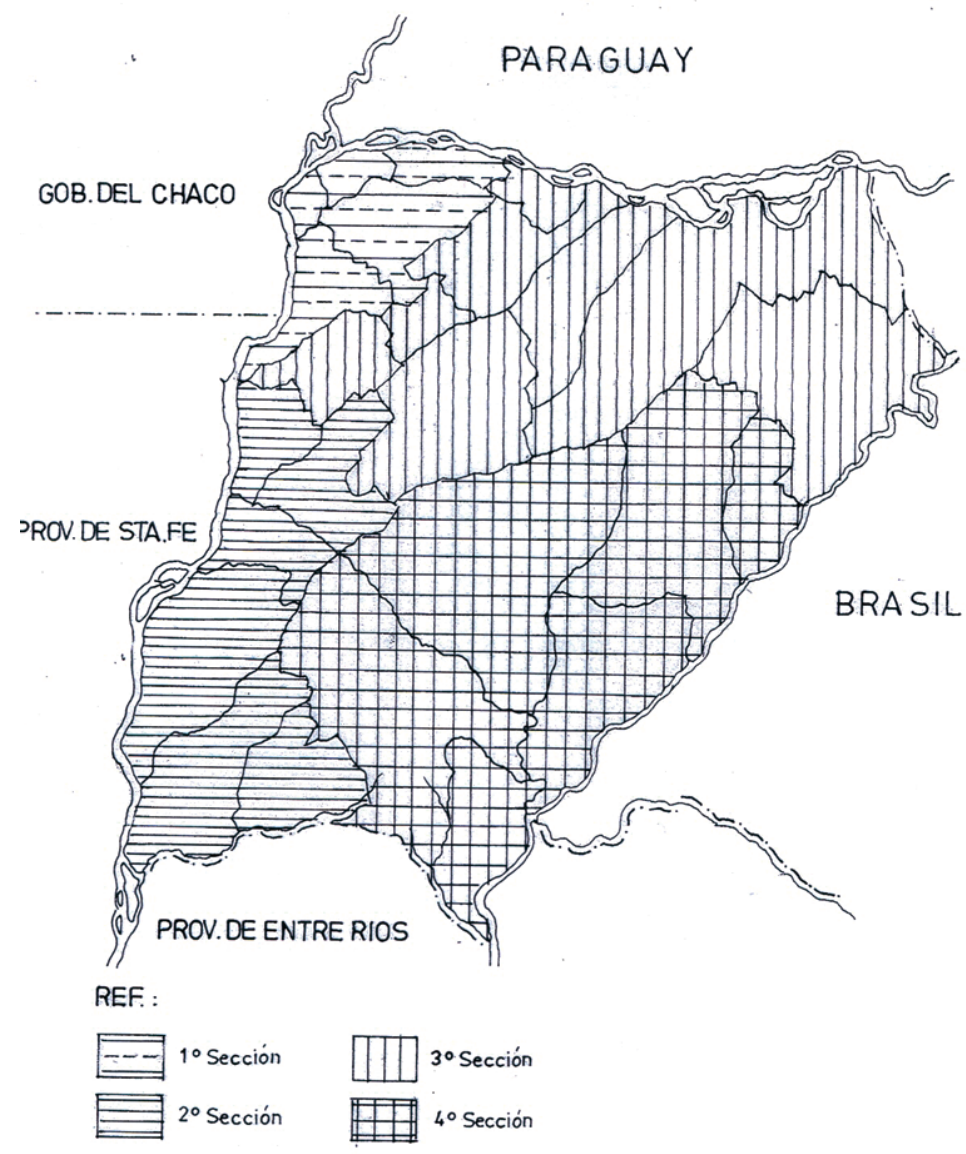

Fuente: El Liberal. Corrientes, 25 de octubre de 1948. p.4

\section{Referencias Bibliográficas}

Aguirre, Orlando Raúl. 2002. "Virasoro, Ballejos y Velazco: Tres perfiles en el peronismo correntino". En: Anales de la Junta de Historia de la provincia de Corrientes $N^{\circ} 4$. Corrientes, Moglia Ediciones.

Aguirre, Orlando Raúl. 2004. "A 60 años del ensayo nacionalista en Corrientes”. En: Anales de la Junta de Historia de la provincia de Corrientes $N^{\circ} 6$. Corrientes, Moglia Ediciones.

Andersen, Martin Edwin. 2002. La policía. Pasado, presente y propuestas para el futuro. Buenos Aires, Sudamericana.

Cantón, Darío. 1975. Elecciones y partidos políticos en la Argentina. Historia, interpretación y balance: 1910- 1966. Buenos Aires, Siglo XXI.

Macor, Darío y TCACH, César (editores), 2003. La invención del peronismo en el interior del país, 
Folia Histórica del Nordeste, № 18 (Resistencia, 2010) IIGHI, CONICET - IH, UNNE

Santa Fe, UNL.

Nohlen, Dieter. 1995. Sistemas electorales y partidos políticos. México, UNAM, Fondo de Cultura Económica.

Panebianco, Angelo. 1982. Modelos de partido. Organización y poder en los partidos políticos. Madrid, Alianza.

Pont, Elena Susana. 1984. El partido Laborista: Estado y sindicatos. Buenos Aires, Centro Editor de América Latina.

Solís Carnicer, María del Mar. 2005. "Los límites a la democratización política. Las elecciones de 1919 en Corrientes, ¿triunfo conservador o derrota radical?”. En: Estudios Sociales № 28, primer semestre de 2005. Universidad Nacional del Litoral, Santa Fe (Argentina).

Solís Carnicer, María del Mar. 2007. "Intransigencia, acuerdos políticos y conflictos institucionales. El fracaso electoral del peronismo en las elecciones de febrero de 1946 en Corrientes". En: I Jornadas Internacionales "Historia y Memoria de la dirigencia política contemporánea, desde 1930 hasta la actualidad”. 2 y 3 de julio de 2007. Córdoba. Versión en CD Rom.

Solís Carnicer, María del Mar . 2008. ““De camaradas a compañeros”. El aporte nacionalista en los orígenes del peronismo correntino”. En: II Jornadas de Historia Política. 25 y 26 de Junio, Montevideo (Uruguay). Versión en CD- Rom.

Solís Carnicer, María del Mar y Sternberg, Carolina. 2004. "La política correntina en los años de la república verdadera. Un análisis del funcionamiento del sistema proporcional a partir de las elecciones legislativas (1913-1930)". En. Política y Gestión, Vol 7, Homo Sapiens, 35- 64 pp. 